\title{
Engaging High School Students in an Engineering Thermodynamics Project
}

http://dx.doi.org/10.3991/ijep.v5i1.4046

\author{
A. P. Preciado Babb ${ }^{1}$, C. Saar ${ }^{1}$, J. Brandon ${ }^{2}$, and S. Friesen ${ }^{2}$ \\ ${ }^{1}$ Galileo Educational Network Association, Calgary, Canada \\ ${ }^{2}$ Werklund School of Education, University of Calgary
}

\begin{abstract}
Efforts for recruiting and retaining students in engineering programs are evident in many postsecondary institutions around the world. These efforts include outreach programs at both elementary and secondary school level, as well as projects that develop capacities beyond technical content-often taught as declarative and procedural knowledge. The mandate of the Galileo Education Network Association includes the design of rich learning environments engaging $K-12$ students in authentic tasks: tasks that resemble the real work of professionals such as engineers. We describe the experience of enacting a sevensession engineering project in thermodynamics with Grade Ten students. Special attention is paid to formative assessment as an essential support for students' learning along the project. The initial project resulted from the collaborationas a means for teacher professional development-between this network association and the mathematics and science teachers in a western Canadian high school. We propose that programs for teacher professional development in mathematics and science should include a focus on tasks that resemble the work of engineering in order to design authentic, engaging learning tasks, and assessing strategies that support and enhance student learning
\end{abstract}

Index Terms-Authentic tasks, Inquiry-based, Projectbased, Formative assessment.

\section{INTRODUCTION}

In the last few years there has been a call for including capacities and competencies of engineers at both undergraduate institutions and in outreach programs aimed at attracting and recruiting students into science, technology, engineering and mathematics (STEM) careers. This call results from an unbalanced number of students interested in these types of careers and the corresponding labour market demand. In the Canadian context, a skills shortage is predicted by 2020 because "the workforce cannot be replaced fast enough by incoming Canadian or experienced internationally trained graduates" [1]. Additionally, there is a trend of lower number of people graduating from these carries, compared to people graduated in other subjects. According to results from Statistics Canada, [2], the percentage of people graduated in STEM subjects in 2007 was considerable lower than those in other subject such as 'Social and behavioural sciences, and law' and 'Business management and public administration.' The percentages in these fields contrast with 'Architecture, engineering and related technologies,' 'Physical and life sciences and technologies,' and 'Mathematics, computer and information sciences,' presented with a different color in the chart in Figure 1. These percentages are consistent to

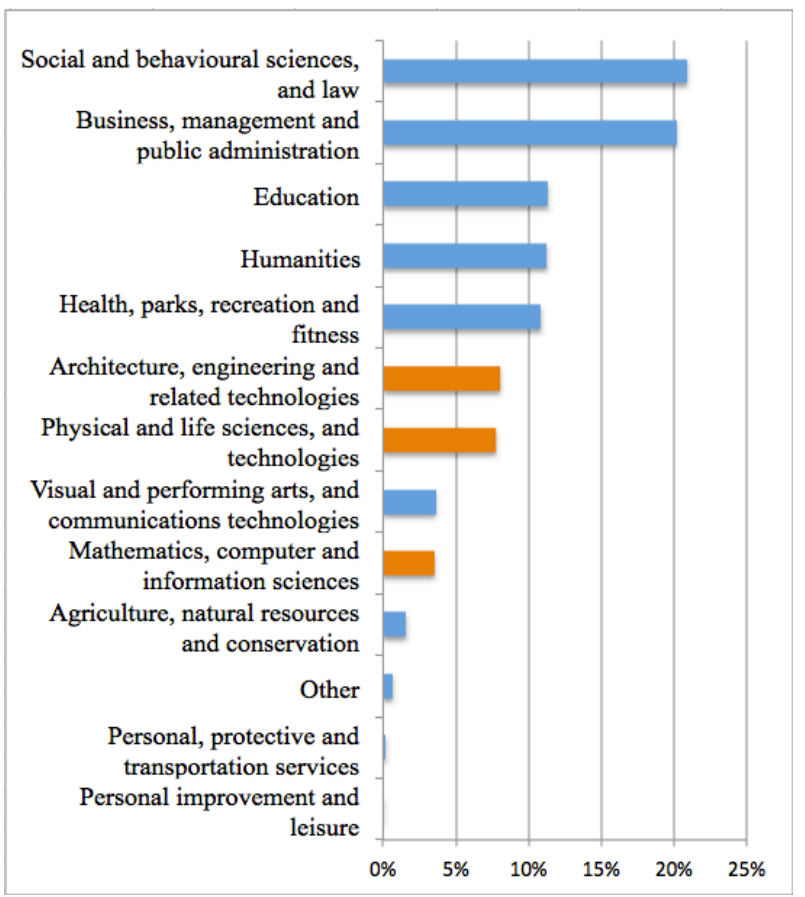

Figure 1. Percentage of university degrees/diplomas/certificates granted by field of study in Canada, 2007. Adapted from [2]

the distribution of graduates reported in 1997 [3]. Instructional style and misconceptions, or even lack of information, of the activities involved in STEM related jobs might be main factors contributing to people's reduced interested in pursuing studies in engineering.

Instructional style at both school and undergraduate levels has traditionally focused on declarative and procedural knowledge, especially for STEM subject areas. For instance, Barak reported in [4] the result of a professional development program for 150 high school teachers. A questionnaire administered during the program revealed that teachers tended to spend much more time in class developing declarative and procedural knowledge (73\%), than conceptual and qualitative knowledge (27\%). The traditional approach of teaching first concepts and definitions has been widely critiqued by academics in educational research and there is still a debate on which type of knowledge students should develop first-see [5]. Although a more productive debate may be about how these two types of knowledge interact in students' learning, there is still a concern about a lack of conceptual knowledge in engineering education. For instance, a recent study reported in [5] involved 587 students in the second year in engineering in Sweden and South Africa. 
The authors found that in both countries students showed higher confidence performing procedural tasks than conceptual tasks, and concluded that: "efforts need to be made to increase students' confidence in conceptually oriented tasks." As educators, we have observed similar tendencies in teaching style and students' confidence performing procedural tasks in Canada.

Stereotypes and lack of contact with people and projects related to engineering may prevent students from pursuing STEM related studies. For instance in [6], by 2005, the curriculum at a school in England and Wales provided students with experiences in science, mathematics or design and technology. However, it did not provide any experience in engineering. Due to the lack of experience with this field, the perception of the work of engineering can be distorted relying on popular stereotypes. Pre-college students' perception about engineering would inform their decisions to pursue a STEM career. Such perceptions can be changed through outreach programs, such as the one presented in [7]. Five hundred sixty-five K - 12 students watched a short computer-based multimedia overview of engineering disciplines. Results showed that students' perceptions changed, leaning to an interest in STEM: the earlier the more influential, especially for girls. Other strategies include the involvement in engineeringlike activities, such as the summer school organized by six European institutions for projects based on creating engineering products reported in [8]. The program included the following essential principles: team-oriented activities; multidisciplinary approach; multicultural approach; problem-based learning; intensive schedule; and industryoriented, including contact with and feedback from experts. Recently, four case studies of partnerships between school and other institutions were described in [9]. Students had a high degree of autonomy and sense of responsibility in engineering-related projects: (1) a high school and a community industry, (2) a network of schools and a global industries, (3) a high school in a provincial city and the local community and small business, and (4) a primary school and broad community. Other programs have focused on teachers, such as the one described in [4], which exemplifies the efforts to outreach engineering education with a focus on higher-order thinking competences, instead of specific subject knowledge. This program included four main components: (1) conceptual knowledge; (2) design process, including simulation, laboratory testing and troubleshooting; (3) systematic documentation, including drafts, tests and improvements; and (4) independent reflective learning.

Partnerships are not easy to establish with every school. An alternative resides in the tasks teachers design for their mathematics and sciences courses. These tasks may be more 'authentic' to the profession of engineering. While it could be hard to engage students in real engineering projects, it is possible to design learning environments involving engineering processes such as: design, tests, trouble-shoot, and documentation of the process. This approach, often identified as project-based learning, have been widely used for engineering education-see for instance [10]. However, critics to this and similar approaches, including inquiry-based learning, have argued that students are left with minimal, of lack of, guidance [11]. In response to this critique, Hmelo-Silver, Duncan and Chinn, [12], stressed the role of scaffolding in projectbased learning: students receive constant guidance and support during the projects. Most recently, Caprapo and Corlu, [13], elaborated on the role of formative assessment in STEM project-based learning, suggestion, among other forms of assessment, the use of rubrics. The importance of formative assessment, as opposed to just summative assessment, has been widely addressed in the literature in education (see for example [14]). For this reason, we consider important to elaborate on the means for formative assessment when describing educational tasks.

The purpose of this paper is to showcase an example of a project in thermodynamics, with a particular focus on the formative assessment provided to students during the project. The enactment of this project is a result of previous collaborations of mathematics and science teachers and mentors from Galileo Educational Network Association (GENA) as a means of teacher professional development. The project was designed during this collaboration and we report on its adaptation and conduction one year later. This paper is aimed at supporting the work of teachers, teacher educators and engineers interested in education in designing authentic class projects that both resemble the work of the engineers and promotes deep understanding of concepts in science. We propose that training teachers for this type of projects should be included in professional development programs, which may be joined by engineers interested in outreach initiatives aimed at preparing and attracting students to STEM related postsecondary paths.

\section{INQUIRY AND TEACHERS' LEARNING}

A key aspect of improving education is to support teachers in the design of rich learning environments using an inquiry-based approach promoting intellectual engagement. GENA has provided teacher professional development programs with an inquiry-based approach to many schools in Canada. This approach is based on the assumption that understanding, and learning, is constructed through joint work and conversation while posing and solving problems, making discoveries and testing them in the course of shared activity [15]. The mentorship provided by GENA as a form of teacher professional development has been informed by the five principles of the Teaching Effectiveness Framework described in [16]. These principles can be summarized as follows: (1) teachers are designers of learning; (2) students assignments are worth their time and attention; (3) assessment improves students learning; (4) teachers promote a variety of interdependent relationships; and (5) teachers improve their practices through collaboration. In this paper we have a particular focus on the second and third principles described in terms of intellectual engagement and formative assessment in he following subsections.

\section{A. Focus on Intellectual Engagement}

We have been particularly interested in promoting intellectual engagement, as described in [17] and [18]. The focus on student engagement springs from an interests on students' life well beyond academic performance at school. While preparing students to future education in post-secondary institutions and potential job markets is an important outcome for school-especially for high school-we concur with Willms, Friesen and Milton that students' engagement at school also impact their daily life [17]. Lack of engagement at school has been associated as 
PAPER

ENGAging High School Students IN AN ENGINEERING THERMOdYNAMICS PROJECT

a source of inequity and linked to violence and social exclusion in Canada and other countries.

Willms, Friesen and Milton, describe intellectual engagement as "a serious emotional and cognitive investment in learning, using higher-order thinking skills (such as analysis and evaluation) to increase understanding, solve complex problems, or construct new knowledge" [17]. The focus on intellectual engagement from GENA is closely related to the authenticity of tasks students are required to conduct at school. The Teaching Effectiveness Framework states that teachers are designer of learning environments in which students engage in doing activities that require different ways of thinking and acting in the world according to particular disciplines or professions: "students think, act and engage with ideas and core concepts in the same ways as historians, chemists, biologists, botanists, writers, journalists, photographers, architects, etc. to make meaningful connections and build deep understanding" [16].

\section{B. Formative assessment}

The assessment principle of the Teaching Effectiveness Framework [16] states that assessment should be incorporated seamlessly through the learning process improving students learning. When assessment is used for this purpose, teachers collect data and provide feedback and scaffolding to students. In this sense, formative assessment, also called assessment for learning, serves a different purpose compared to summative assessment, also called assessment of learning. The assessment principle of the framework stresses the importance of using varied forms of formative assessments to inform instructional decisions. This principle suggests that assessment criteria should be designed in collaboration with students, involving expertise from the corresponding discipline, and reflecting high quality standards of authentic work. Finally, this principle indicates that students must have access to the assessment criteria receiving ongoing, specific feedback through the learning process. A common tool for formative assessment is the design and use of a rubric: a chart describing different levels of achievement corresponding to selected criteria for a specific learning task.

\section{THE DESIGN-BASED RESEARCH}

For three years, GENA supported teachers at one particular high school in western Canada. Examples of the projects designed in collaboration with the teachers are described in [18]. This initiative included a participatory design-based research ([19]) in which we worked with teachers and students in projects aimed at student intellectual engagement. The purpose of the research was to deepen our understanding on how student learning and engagement are impacted when teachers are provided with GENA's professional development. In design-based research in education real educational contexts and innovations are studied involving multiple iterations of design and testing in collaboration with researchers and practitioners [19]. In contrast to other forms of research in which students and teachers are merely research subjects, in participatory design-based research teachers may play an important role in the design of the innovations. The thermodynamics project described in this paper was codesigned with the mathematics and science teachers in its second iteration one year after its initial design. While GENA participated in the original design, teachers worked independently in the refinement and adaptation for the second implementation, having a more protagonist role in the design and of the project.

The data for the overall three-year design-based research is extensive and include both quantitative and qualitative sources - see [18] for more information. The data for the case reported in this paper comprises: class observations, interviews with teachers and students, documents used for the project, and filed notes taken by one research member who attended the sessions of the project. Class observations were conducted with a protocol developed and tested during the first and second year of the initiative. At least two researchers participated in each class observation and discussed and resolved differences thereafter. The class observation included a 0-4 Likert scale in the following constructs:

Intellectual Investment: What is the level of intellectual investment that the lesson requires of students at this point? Characterize the investment on a scale from "passive," 0 , such as that required for copying notes and recall of information, to more challenging "flow zone" type, 4 , of work that is absorbing, creatively energizing, and requiring thought processes that demand analysis, synthesis, conjecture, reasoned judgment, creation and/or innovation.

Instructional Style: What is the general instructional style of the lesson at this point? Characterize the style on a scale from completely "teacher controlled," 0 , and directed to "responsive," 4 , where the teacher is fully present and responsive to the learning as it emerges.

Authenticity: Do tasks and activities have value (personal, social or aesthetic) beyond school in "real-world" contexts or is it more appropriately characterized as "artificial" with little relevance or purpose outside of a classroom? The values ranged from 0 to 4 corresponding to 'artificial' and 'real world,' respectively.

Class observations were conducted during the second semester of the third year of the professional development program. These observations included two groups for each of the following subjects: Mathematics, Science, Social Sciences, and Humanities. High levels of student intellectual engagement, instructional styles and authenticity were identified during the first session of the Thermos Project and we decided to document the whole activity. Figure 2. shows a graph with the results of the class observation for the eight lessons - two different lessons for each subject. The third column corresponds to the first session of the Thermos project, which is higher than any other observed lesson at this time. For this reason, we decided to document the enactment of this project.

Teachers and student interviews were conducted at the end of the year as part of the broader research. In the interviews students were asked about the most engaging activities during the year. Interviews were transcribed and verified for accuracy. For the case reported in this paper, the excerpts of the interviews related to the Thermos project were identified and analysed in terms of their potential evidence of student intellectual engagement, authenticity and relevance of the task, and assessment practices. Excerpts of these interviews are also included in this paper. These interviews are, however, limited as they referred to the whole experience during the year, not just this project, and only five students accepted, or were able, to participate. 


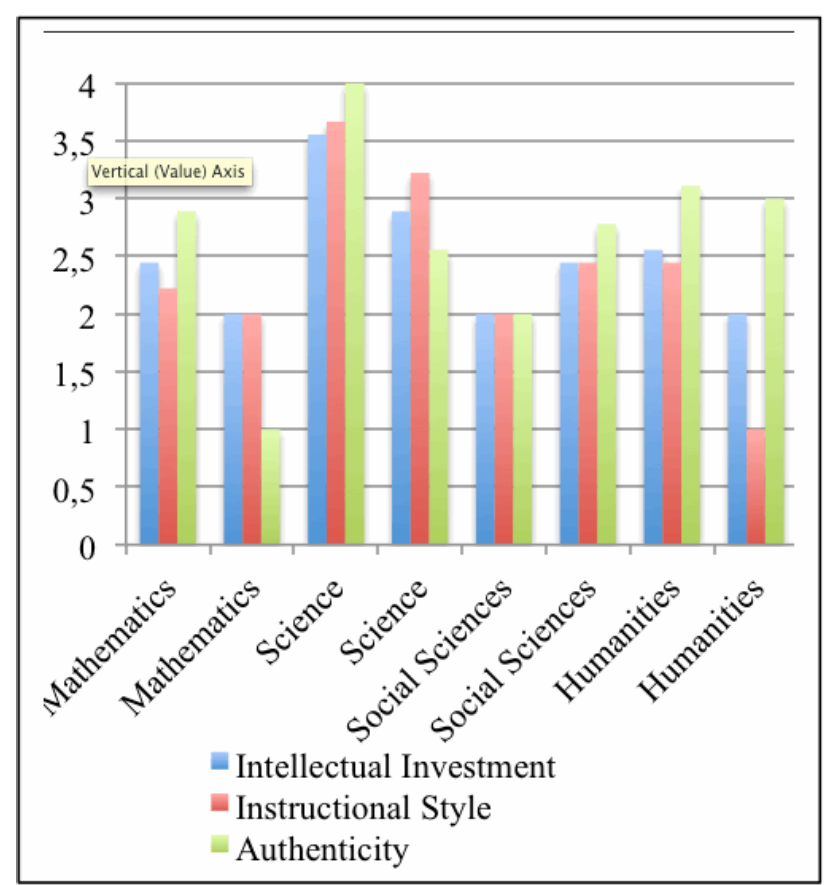

Figure 2. Class observation data collected to different teacher for Grate Ten students.

Documents related to the thermos project and filed notes of one of the researchers were used to write a narrative for the whole process. This narrative was send to one of the teachers as a means to verify accuracy and interpretation of the events.

Names of participant teachers, students and school are not disclosed in order to warrant anonymity and confidentiality. The photographs included in this paper do not correspond to the original research data. Many examples of the collaborative work of GENA with teachers are documented in videos available online [20]. The photographs included in this paper were extracted from one of these videos and serve to exemplify the type of artefacts and processes involved in the Thermos project.

\section{THE THERmos Project}

The purpose of the Thermos Project was to engage students in an authentic engineering task. Students had to create a thermos with particular specifications using raw materials during seven sessions. The project included a discussion of the first and second laws of thermodynamics in relation with the project. A very important characteristic of this task was its connection to real work in science and engineering. Science Program of Studies in Alberta emphasises the development of the nature of science highlighting its changing character based on interpreting new evidence, paradigms, language, and hypothesis testing. The program also stresses skills in including: initiating and planning, performing and recording; analysing and interpreting; and communication and team work. These skills are consistent to the skills in engineering promoted in different outreach programs aimed at engage students in work that resembles authentic engineering tasks. In this section we present a description of the project, followed by selected excerpts from students and teachers interviews in connection to students intellectual engagement, the authenticity of the task, and the formative assessment used to support students' learning.
The program of studies for Grade Ten in Alberta has a focus on energy conversion in the unit corresponding to thermodynamics. Energy conservation is a topic of Grade Eight and the Thermos Project was used as an introduction to the energy transformation and efficiency in Grade Ten, serving as a bridge between previous knowledge and a new topic. In both grade levels the first and second laws of thermodynamics were a part of the content.

In the first session students were introduced to the work in science and engineering and to the Thermos Project. They were asked to construct a table out of newspaper and tape with particular requirements for size and capacity to support a specific weight. Working by teams, they tested their tables with some heavy materials and compared different designs. This session, on Friday afternoon, was not intended to introduce any particular topic in science, but rather to reflect on the process of design, construction, redesign and improvement. Students' initial tables were tested and improved designs were created thereafter. Teachers led a reflection of the steps involved in building the table: planning, constructing, collaborating, and testing. The authenticity of this task was not based on any particular content in science. Rather, it was intended to show a process that resembles the exploration and innovation process in science and engineering. Students worked diligently and had fun building their tables by teams. Teachers were responsive providing feedback to each team and challenging students to improve their designs.

After the reflection on the process of engineering design, teachers presented the "How science works: The flowchart" interactive diagram developed by the California Museum of Paleontology ([21]). The flowchart comprises four interconnected components: exploration and discovery, benefits and outcomes, community analysis and feedback, and testing ideas. Based on this diagram and the reflection on the construction of the table, students were required to create a rubric for assessment for this project, which was a common practice in this class since the beginning of the year. This rubric was later refined by the teacher and used to formatively assess - feedbackstudents' designs. The final rubric incorporated five elements: research initial design, troubleshooting, analysis of final project, science connections, and real life applications. Each component was described into three levels using the descriptors: keep working; getting there; and got it.

At the end of this first session teachers introduced the purpose of the Thermos Project using the following instructions: "Your challenge is to design and build a device that will most efficiently conserve energy in hot water. In this project you will explore the following thermodynamic concept: energy flow within a system; first and second laws of thermodynamics, efficiency of a thermos device; and need for energy efficient devices in society." The thermos had to satisfy physical requirements: (1) Must not be any larger than $20 \mathrm{~cm}$ length, $20 \mathrm{~cm}$ with, and $35 \mathrm{~cm}$ height; (2) must hold a thermometer at all times; (3) must be portable; (4) must hold a maximum of $500 \mathrm{~mL}$ of hot water; (5) must not use an external power source (batteries, pug-ins, etc); and (6) must not be (or contain) a device already marketed as a thermos.

The process of design required particular specifications. Design plans had to be submitted and reviewed prior start building the thermos. Upon completion of the thermos, group assessment was performed. Daily documentation 
was part of the process in a form of students' choicedigital formats were highly encouraged.

The Design Log included the following elements: daily documentation of techniques and troubleshooting; research surrounding thermal energy devices; possible design options; pictures and photographs; analysis of initial testing; final design and testing data; and analysis of efficiency of final design. The analysis of final design included a discussion around the first and second law of thermodynamics and how it related to the design. Examples of digital blogs are shown in Figure 3. .

In the second day students toured an eco-friendly house with an expert explaining the systems and thermal efficiencies used in the house. A specialist architect explained the different features and innovation in this house. Insulation was an important feature as the local weather reaches winter temperatures of -40 Celsius degrees. The visit served as source for ideas and inspiration for the Thermos Project.

The third and fourth days were devoted to design, construction, re-design and construction of new thermos. Students used a variety of different materials (Figure 4. ) and designs, which were tested for efficiency. Former engineers visited the classroom to provide feedback and suggestions to each team. The visit of these external 'experts' was an important component of the project as connections to expertise is stressed in the Teaching Effective-

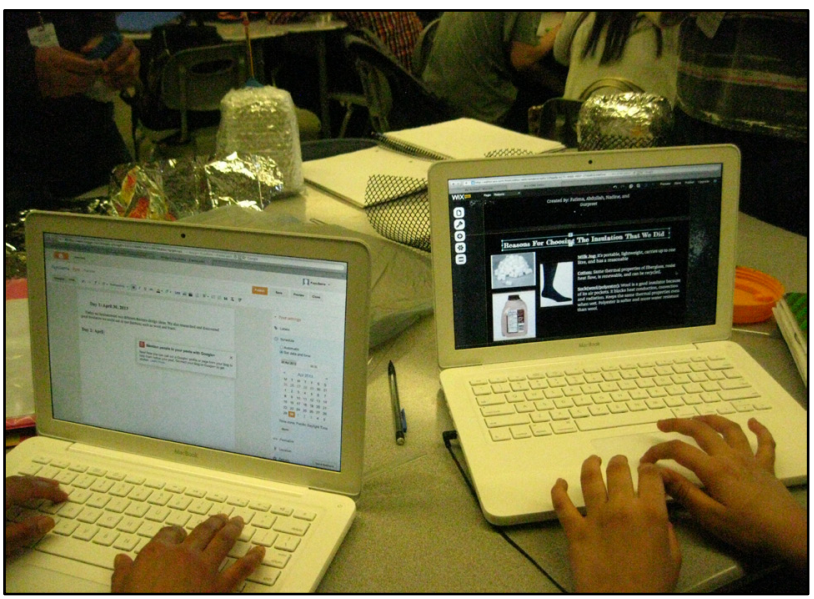

Figure 3. Example of Daily Blogs

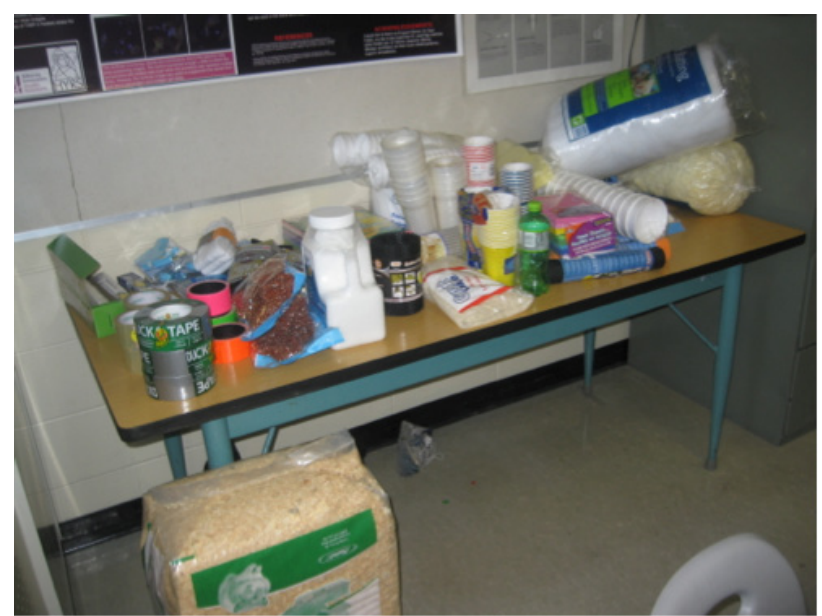

Figure 4. Materials provided for the construction of the thermos in the second session of the project. ness Framework. In these sessions teachers and engineers gave formative assessment on both the products and the processes students were engaged in.

As indicated before, students had to wait until they received feedback on the designs before initiating the construction of the thermos. These designs were drawn using different tools, from paper and pencil to digital devices (Figure 5. and Figure 6. ), and they also had to be based on previously conducted research on the type of materials and thermodynamic principles used in actual thermal devices.

In the fifth and sixth sessions students worked on improving their designs based on the feedback they received the days before and additional research they undertook. During this process they tested the new thermos and compared this against the results of their initial designs. Figure 7. shows an example of an improved design compared with the initial design. It is clear that the second design is more elaborate and has better explanations in the drawing. Figure 8. shows an example of the construction of one thermos based on the improved design.

The seventh session was devoted to testing the best thermos, checking the specification and triggering further thinking. The final thermoses were assessed and questions were posed to students triggering further thinking. For instance, one teacher challenged a team on whether the dimensions of their thermos might be reduced to make it

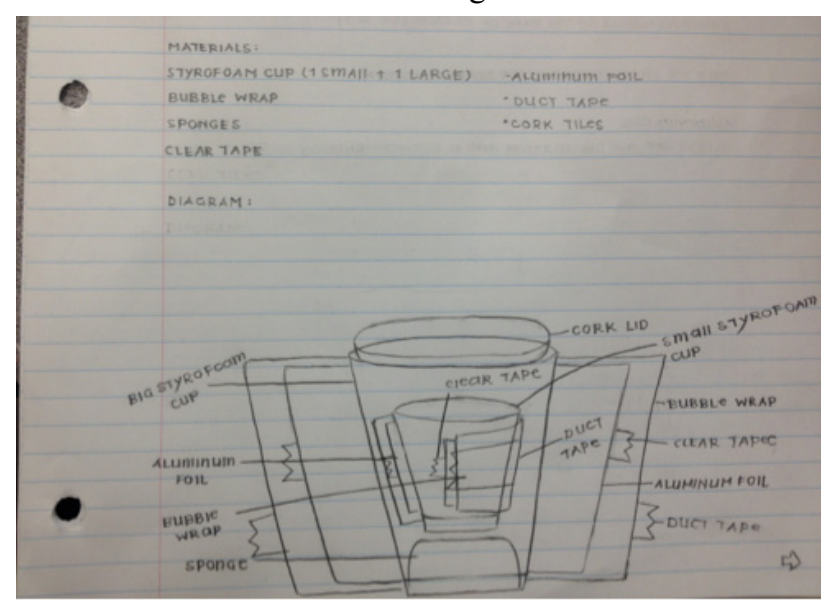

Figure 5. Example of one student's design in paper.

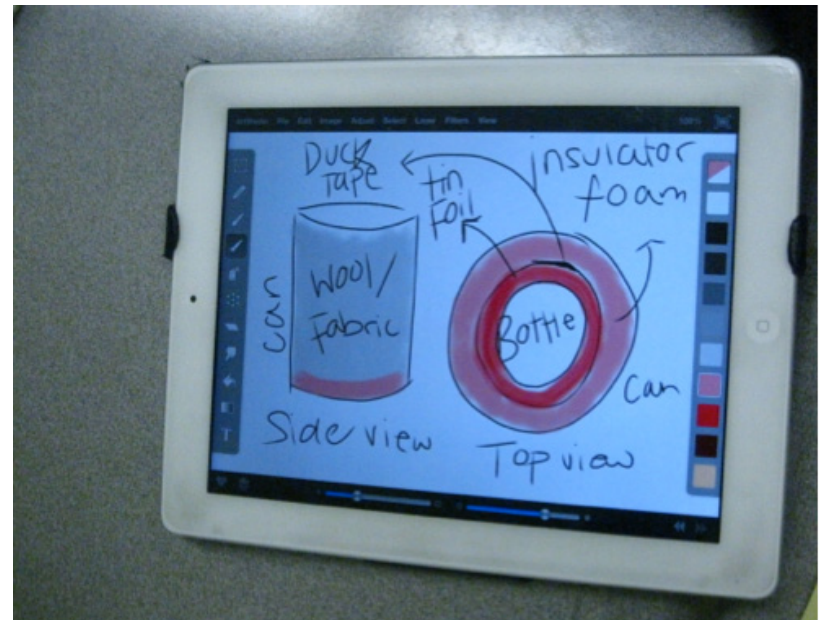

Figure 6. Example of student design using a tablet. 
PAPER

ENGAging High School Students IN AN ENGINEERING THERMOdYNAMICS PROJECT

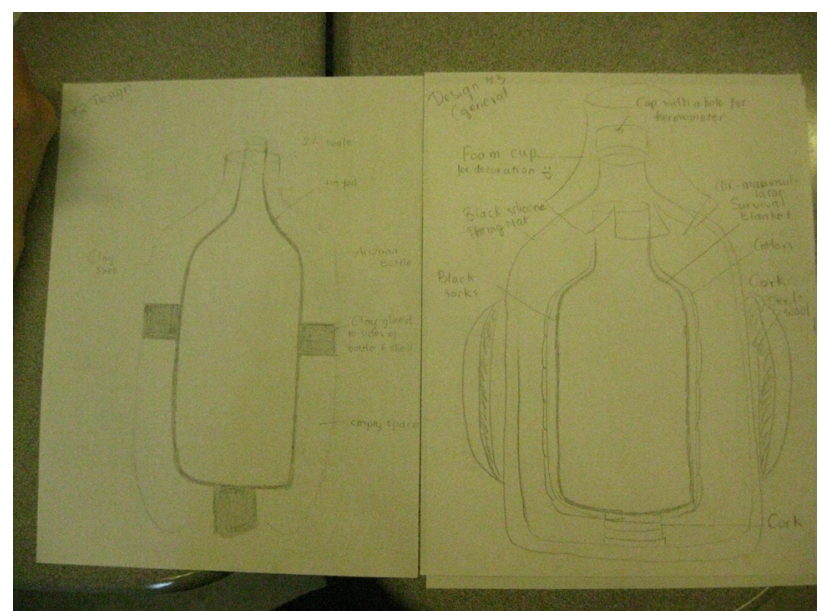

Figure 7. Comparison of two different designs.

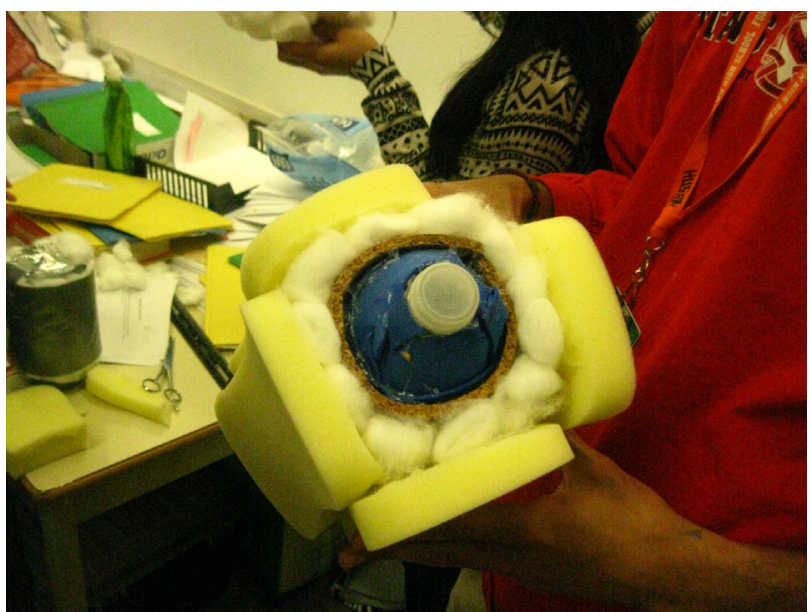

Figure 8. Example of the use of materials for building the thermos.

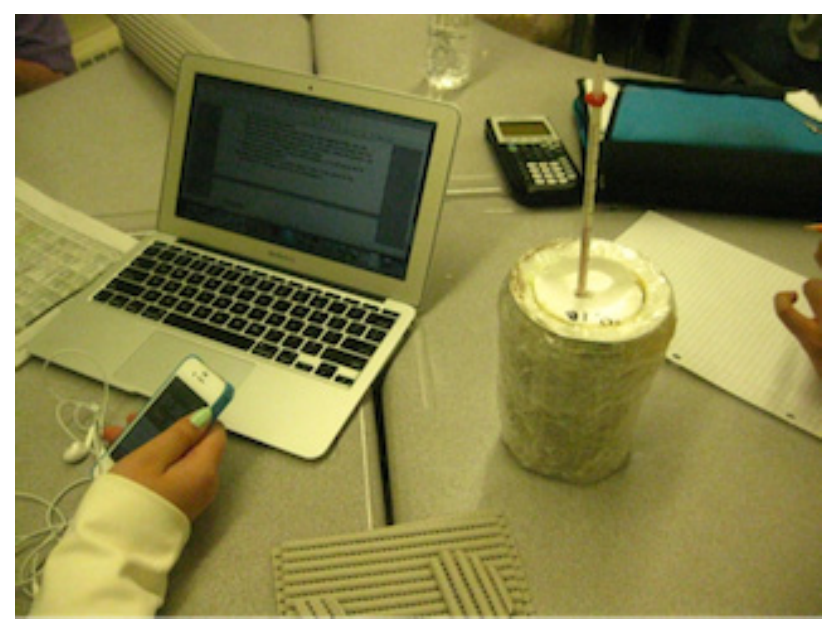

Figure 9. Example of test for efficiency in final thermos.

more portable. One team also considered the use of more sustainable materials for the thermos for a lower ecological impact.

Students used a variety of tools to measure, document and analyze efficiency in their thermos. Figure 9. shows the testing of a thermos in which the student used the cellphone to measure time and reposted in the computer the results.
Although the final tests of the thermos was done by this last session, students were still required to finalize the project submitting both a Design Log, including data analysis and interpretation from the thermodynamics laws, and a self-reflection on Energy Efficiency Devises.

According to the teachers who participated in the design and implementation of this task this time and the year before, student engagement was stronger this second time and there was a more deliberate focus on the work of engineering, as we can read in the following quotation.

Students had a stronger understanding of thermodynamics and the importance thereof than in previous years. I also thought that students did a much better job on their thermoses this year than they did last year. The biggest difference this year was the initial engineering task that got students thinking like engineers and highlighted the importance of design, testing, and troubleshooting (Grade Ten science teacher).

In the interviews with students by the end of the year one female student commented on this particular project when asked about an example of a school-work that was really memorable.

I think that Thermos was fun to make, we got materials and we got to make our own thermos and test its efficien$c y$, so it set us up to what we were going, we are making experiment unlike getting to test them out, like what they do in real life, so trying to make us feel like we were actually engineers or something and learning the process of how everything was set up.

Just the experience how it was set up thing, how our teachers set everything up, made it feel like we were actually like engineers. Normally that, it sets us up for what we're going to continue in life like if you're going to be an engineer, you're not going to be doing it by yourself, it was a group and that's why we were in a group and we got to share ideas off of each other (Female Grade Ten student).

During the interview students were asked the following question: "If brain-power was measured as a percentage, generally what percentage of your brain power do you think you typically use at school? Why is that? Could you give an example when you actually used a high percentage of your brain power?" The previous female student indicated that during the thermos she used a very high percent of her 'brain power.'

Another female student also commented on the thermos project when asked about an example when she used a high percent of her 'brain power.'

I would also have to say the thermos, we tried most of different things, one of our issues was that we forgotten about the 500 milliliter rule and we had to have this thermos built, so we had to figure out a way to somehow put another bottle in the thermos that we had made, we basically took a 500 milliliter bottle, squished it up, shoved it into the other tube bottles that we had made up. We actually poured hot water in it to expand the bottle, so that one of the interesting ideas that we came up with and we wrapped it in duct tape eight times.

It was a very fun project, I was very into that one and I just feel that was one of the ones that I put a lot into it (Female students).

It is important to remember that we conducted these interviews at the end of the year and focused on the whole 
high school experience, not just on science. The previous transcripts show, in students' voices, how these two students were: intellectually invested during the project; and felt it as authentic to the work of engineers.

Despite the fact that very few students were interviewed at the end of the course, it is worth noting that these two females students remembered the Thermos Project as one which required high levels of 'brain power,' and one of them actually found this project as the most memorable in the whole year. The perspectives of these two female students contrast with the traditional prototype of engineering as a male subject.

\section{DISCUSSION}

The Thermos Project was the result of the collaborative design of teachers and GENA mentors as a means of teacher professional development. This project was strongly focused on promoting students' understanding of the job of engineering, in the form of an authentic science school project. During the project students engaged in: research, design, test, trouble-shooting, and documentation in collaboration with their peers. They had the chance to meet experts in the field during the eco-friendly house visit and the feedback sessions in which former engineers visited the classroom. The whole process was based on the authentic work of practising engineers.

Formative assessment was an important part of the project. Students participated in the design of the assessment rubric, based on a description of scientific designconsistent with the design process in engineering. Both teacher and external experts provided feedback to the designs before students started building the thermos. We consider formative assessment as an important component of both project-based and inquiry-based learning, and argue that reports of these type of learning experience would be enriched by descriptions of the corresponding student guidance and scaffolding, as part of formative assessment.

The role of the teacher in enacting this project was crucial, as well as the support provided by GENA in the design of inquiry-based learning environments. Focusing on this type of support not only helps teachers to improve their practice in general, but also provides a means to engage students in authentic tasks. In the case of science, these tasks can be designed in a way that parallels the actual work of an engineer. This is particularly relevant for promoting STEM careers for which outreach programs have been implemented internationally.

Efforts for recruiting students in engineering programs may be expensive and hard to accomplish. Creating partnerships between schools and other institutions is a way of outreaching the job of engineers. However, this may not be possible for all schools. We propose that teachers can develop learning environments authentic to the work that professionals do. Such environments can be designed in collaboration with other teachers and specialists in the form of professional development. The case reported in this paper is just and example of how teacher professional development can impact on students' high school experience, providing engaging learning environments that resembling the work, and skills, of engineering. The benefit of this type of task would impact on both student learning and increment of interest in STEM careers.
We believe that the combined work of engineers and educators has a huge potential. Stakeholders interested in engineering education may participate in the professional development of mathematics and science teachers as a means of both student learning and engineering outreach strategies.

Finally, from the Thermos Project documented in this paper it is possible to identify further venues of research and implementation of similar school activities. For instance, how do get students to see themselves as engineers? Quantitative studies on students' perceptions before and after engineering at school would serve as a measure of the students change of perceptions and whether they would choose to conduct STEM studies in the future. Teacher education itself represents a challenge. Many teachers are still reluctant to shift from traditional teaching styles with an exclusive focus on factual and procedural knowledge. Collaborations of engineers and teacher in the enactment of teacher education programs may be implemented and research, as well.

\section{REFERENCES}

[1] Prism Economics and Analysis, "The engineering labour market in Canada: Projections to 2020." p. 97, 2012.

[2] Statistics Canada, "Number of university degrees/diplomas/certificates granted, by sex and field of study, Canada and provinces, 2007," 2009.

[3] Statistics Canada, "Education Indicators in Canada: Fact Sheets," 2009. [Online]. Available: http://www.statcan.gc.ca/pub/81-599x/81-599-x2009003-eng.htm.

[4] M. Barak, "From 'doing' to 'doing with learning': Reflection on an effort to promote self-regulated learning in technological projects in high school," Eur. J. Eng. Educ., vol. 37, no. 1, pp. 105116, Mar. 2012. http://dx.doi.org/10.1080/03043797.2012.658759

[5] J. Engelbrecht, C. Bergsten, and O. Kågesten, "Conceptual and procedural approaches to mathematics in the engineering curriculum: Student conceptions and performance," J. Eng. Educ., vol. 101, no. 1, pp. 138-162, 2012. http://dx.doi.org/10.1002/j.21689830.2012.tb00045.x

[6] N. Smith and M. Monk, "Attracting tomorrow's engineers: An evaluation of a scheme to enhance recruitment into engineering," Eur. J. Eng. Educ., vol. 30, no. 2, pp. 233-243, May 2005. http://dx.doi.org/10.1080/09603120500115314

[7] A. M. Johnson, G. Ozogul, M. D. DiDonato, and M. Reisslein, "Engineering perceptions of female and male K-12 students: Effects of a multimedia overview on elementary, middle-, and highschool students," Eur. J. Eng. Educ., no. September, pp. 1-13, Jul. 2013.

[8] P. G. Larsen, J. M. Fernandes, J. Habel, H. Lehrskov, R. J. C. Vos, O. Wallington, and J. Zidek, "A multidisciplinary engineering summer school in an industrial setting," Eur. J. Eng. Educ., vol. 34, no. 6, pp. 511-526, Dec. 2009. http://dx.doi.org/10.1080/03043790903150687

[9] J. Watters and C. Diezmann, "Community partnerships for fostering student interest and engagement in STEM," J. STEM Educ., vol. 14 , no. 2 , pp. 47-56, 2013.

[10] J. A. Álvarez, J. Segundo, C. Álvarez, J. C. Arellano, and A. A. Pérez, "Evaluation of the Use of Two Teaching Techniques in Engineering," Int. J. Eng. Pedagog., vol. 4, no. 3, pp. 4-10, 2014. http://dx.doi.org/10.3991/ijep.v4i3.3287

[11] P. A. Kirschner, J. Sweller, and R. E. Clark, "Work: An Analysis of the Failure of Constructivist, Discovery, Problem-Based, Experiential , and Inquiry-Based Teaching," Educ. Psychol., vol. 41, no. 2, pp. 75-86, 2006. http://dx.doi.org/10.1207/s153269 $85 \mathrm{ep} 4102 \_1$

[12] C. E. Hmelo-Silver, R. G. Duncan, and C. A. Chinn, "Scaffolding and Achievement in Problem-Based and Inquiry Learning: A Response to Kirschner, Sweller, and Clark (2006)," Educ. Psychol., vol. 42 , no. 2 , pp. $99-107$, Apr. 2007. http://dx.doi.org/10.1080/ 00461520701263368 
[13] R. M. Capraro and M. S. Corlu, "Changing views on assessment for STEM project-based learning," in STEM Project-Based Learning: An Integrated Science, Technology, Engineering, and Mathematics (STEM) Approach (2nd Edition), 2nd ed., R. M. Capraro, M. M. Capraro, and J. R. Morgan, Eds. Rotterdam, The Netherlands: Sense Publishers, 2013, pp. 109-118. http://dx.doi.org/10.1007/978-94-6209-143-6_12

[14] D. William, Embedded formative assessment. Bloomington, IN: Solution Tree Press, 2011, p. 200.

[15] Galileo Educational Network Association, "What Is Inquiry?" [Online]. Available: http://galileo.org/teachers/designinglearning/articles/what-is-inquiry/. [Accessed: 30-Sep-2013].

[16] S. Friesen, What did you do at school today? Teaching Effectiveness: A framework and Rubric, no. May. Toronto, Canada: Canadian Education Association, 2009.

[17] J. D. Willms, S. Friesen, and P. Milton, What did you do at school today: Transformin classrooms through social, academic and intellectual engagement, no. May. Toronto, Canada: Canadian Education Association, 2009.

[18] A. P. Preciado Babb, C. Saar, C. Marcotte, J. Brandon, and S. Friesen, "Using mobile technology for fostering intellectual engagement," Int. J. Interact. Mob. Technol., vol. 7, no. 3, p. 46, Jun. 2013. http://dx.doi.org/10.3991/ijim.v7i3.2888

[19] T. Anderson and J. Shattuck, "Design-Based Research: A Decade of Progress in Education Research?," Educ. Res., vol. 41, no. 1, pp. 16-25, Feb. 2012. http://dx.doi.org/10.3102/0013189X 11428813
[20] Galileo Educational Network Association, "Classroom Examples," 2014. [Online]. Available: http://galileo.org/classroom-examples/.

[21] University of California Museum of Paleontology, "How science works: The flowchart," 2013. [Online]. Available: http://undsci.berkeley.edu/article/scienceflowchart. [Accessed: 10Nov-2013].

\section{AUTHORS}

A. P. Preciado Babb is a postdoctoral fellow at Galileo Educational Network Association, University of Calgary, Alberta, Canada (e-mail: apprecia@ucalgary.ca).

C. Saar with Galileo Educational Network Association, University of Calgary, Alberta, Canada (e-mail: cysaar@ucalgary.ca).

J. Brandon with Werklund School of Education, University of Calgary, Alberta, Canada (e-mail: jbrandon@ucalgary.ca).

S. Friesen with Werklund School of Education, University of Calgary, Alberta, Canada (e-mail: sfriesen@ucalgary.ca).

Submitted 15 July 2014. Published as resubmitted by the authors 14 February 2015. 